\title{
Sleep Disturbances in Functional Gastrointestinal Disorders
}

\author{
Seiji Futagami, Hiroshi Yamawaki, Satomi Hashimoto and Katsuhiko Iwakiri
}

Key words: gastroesophageal reflux disease, sleep disturbance, non-erosive reflux disease, functional gastrointestinal disorder, anxiety, depression

(Intern Med 55: 1509-1510, 2016)

(DOI: 10.2169/internalmedicine.55.6223)

Sleep disturbance is a common medical problem and has been associated with several diseases, including pulmonary disease, gastroesophageal reflux disease (GERD) and fibromyalgia. It causes significant morbidity, as evidenced by the increased need for general medical treatment and mental health treatment for emotional problems. A number of studies have found an association between sleep disorders and functional gastrointestinal (GI) disorders (1-5). Sleep disturbance is known as an important extra-esophageal complication in patients with GERD. It is also associated with impaired health-related quality of life (QOL) and often found in older subjects.

GERD has been reported to be associated with interruptions of sleep, sleepiness and consequent impaired work productivity. Lee et al. have also identified that heartburn and regurgitation have different impacts on sleep disturbances, eating or drinking problems, work interference, and QOL (6). In addition, Iwakura et al. have reported that the prevalence of sleep disturbances was significantly higher in GERD patients $(66 / 124,53.9 \%)$ than in those without this condition (89/126, 39.3\%) (7). Interestingly, they demonstrated that the prevalence of depression and anxiety was higher in both GERD and non-GERD patients with sleep disturbances than in those without sleep disturbances (7). They also addressed the issue that there were no differences in the prevalence rates of depression and anxiety between GERD and non-GERD patients (7). Specifically, they speculated that depression and/or anxiety are associated with sleep disturbances, but are not specific to GERD patients (7). Jansson et al. have also presented results similar to those of Iwakura et al. (8). However, the exact reasons for the association between daytime sleepiness and GERD remained unclear.

The effects of proton pump inhibitor (PPI) therapy on the objective sleep parameters in GERD patients are controversial and have not been precisely elucidated in Japanese patients with this condition. Johnson et al. showed that esome- prazole significantly improved nighttime heartburn and GERD-associated sleep disturbances as well as improved sleep quality when compared with a placebo (9). Orr et al. also used polysomnography to determine the effects of rabeprazole treatment and found that such treatment improved sleep quality (10). Meanwhile, Chand et al. reported that the administration of esomeprazole was not associated with sleep efficiency (11) and Jha et al. also reported that esomeprazole had no impact on the duration of the recumbentawake period and the frequency or duration of awakening to a conscious states in GERD patients (12). The reasons for these discrepancies in previous studies are unknown. Although the evaluation of sleep disturbances is important, the Pittsburgh Sleep Quality Index (PSQI) score (13) is commonly used to assess subjective sleep disturbances, but polysomnography is the gold standard for assessing sleep parameters.

Jha et al. also reported that a subgroup exhibiting nonerosive reflux disease (NERD) with regurgitation had a significantly higher rate of impaired daily activity than a subgroup exhibiting erosive esophagitis with regurgitation particularly, regarding eating or drinking problems and work interference (12). In Japan, patients with NERD as well as erosive esophagitis were also reported to be affected by sleep impairment $(1,2)$. In addition, subjects with NERD have total QOL scores similar to those of patients with erosive esophagitis $(1,14)$. Further studies will be needed to clarify whether the mechanisms of sleep disturbance in NERD patients differ from those in erosive esophagitis.

The authors state that they have no Conflict of Interest (COI).

\section{References}

1. Fujiwara Y, Kohata Y, Kaji M, et al. Sleep dysfunction in Japanese patients with gastroesophageal reflux disease: prevalence, risk factors, and efficacy of rabeprazole. Digestion 81: 135-141, 2010. 
2. Murao T, Sakurai K, Mihara S, Marubayashi T, Murakami Y, Sasaki Y. Lifestyle change influences on GERD in Japan: a study of paticipants in a health examination program. Dig Dis Sci 56 2857-2864, 2011

3. Fass R, Fullerton S, Tung S, Mayer EA. Sleep disturbances in clinic patients with functional bowel disorders. Am J Gastroenterol 95: 1195-2000, 2000

4. Goldsmith G, Levin JS. Effect of sleep quality on symptoms of irritable bowel syndrome. Dig Dis Sci 38: 1809-1814, 1993.

5. Futagami $\mathrm{S}$, Yamawaki $\mathrm{H}$, Izumi $\mathrm{N}$, et al. Impact of sleep disorders in Japanese patients with functional dyspepsia (FD): nizatidine improves clinical symptoms, gastric emptying and sleep disorders in FD patients. J Gastroenterol Hepatol 28: 1314-1320, 2013.

6. Lee SW, Lien HC, Lee TY, Yang SS, Yeh HJ, Chang CS. Heartburn and regurgitation have different impacts on life quality of patients with gastroesophageal reflux disease. World J Gastroenterol 20: 12277-12282, 2014.

7. Iwakura N, Fujiwara Y, Shiba M, et al. Characteristics of sleep disturbances in patients with gastroesophageal reflux disease. Intern Med 55: 1511-1517, 2016.

8. Jansson C, Nordenstedt H, Wallander MA, et al. A populationbased study showing an association between gastroesophageal reflux disease and sleep problems. Clin Gastroenterol Hepatol 7:
960-965, 2009

9. Johnson DA, Orr WC, Crawley JA, et al. Effect of esomeprazole on nighttime heartburn and sleep quality in patients with GERD: a randomized, placebo-controlled trial. Am J Gastroenterol 100: 1914-1922, 2005.

10. Orr WC, Goodrich S, Robert J. The effect of acid suppression on sleep patterns and sleep-related gastro-oesophageal reflux. Aliment Pharmacol Ther 21: 103-108, 2005.

11. Chand N, Johnson DA, Tabangin M, Ware JC. Sleep dysfunction in patients with gastro-oesophageal reflux disease: prevalence and response to GERD therapy, a pilot study. Aliment Pharmaocol Ther 20: 969-974, 2004.

12. Jha LK, Maradey-Romero $C$, Gadam $R$, et al. The effect of antireflux treatment on the frequency of awakenings from sleep in patients with gastroesophageal reflux disease. Neurogastroenterol Motil 27: 237-245, 2015.

13. Doi Y, Minowa M, Uchiyama M. Development of the Japanese version of the Pittsburgh Sleep Quality Index. Seishinka Chiryougaku (Jpn J Psychiatr Treat) 13: 755-763, 1998 (in Japanese).

14. Kulig M, Leodolter A, Vieth M, et al. Quality of life in relation to symptoms in patients with gastrooesophageal reflux disease: an analysis based on the ProGERD initiative. Aliment Phramacol Ther 18: 767-776, 2003.

(C) 2016 The Japanese Society of Internal Medicine http://www.naika.or.jp/imonline/index.html 